\title{
ESTIMASI RATA-RATA LAMA SEKOLAH TINGKAT KECAMATAN DI KABUPATEN PADANG PARIAMAN DENGAN METODE EMPIRICAL BEST LINEAR UNBIASED PREDICTOR
}

\author{
(ESTIMATION OF MEAN YEARS OF SCHOOLING FOR SUB-DISTRICT LEVEL \\ IN PADANG PARIAMAN DISTRICTS WITH METHOD \\ EMPIRICAL BEST LINEAR UNBIASED PREDICTOR)
}

\author{
Rita Diana', Rory ${ }^{2}$ \\ Badan Pusat Statistik Provinsi Sumatera Barat ${ }^{1}$ \\ Badan Pusat Statistik Kabupaten Padang Pariaman² \\ E-mail: rita.diana@bps.go.id
}

\begin{abstract}
ABSTRAK
Rata-rata lama sekolah penduduk umur 25 tahun ke atas merupakan salah satu indikator yang menggambarkan tingkat pendidikan penduduk secara keseluruhan. Dari 19 kabupaten/kota di Sumatera Barat, Kabupaten Padang Pariaman memiliki rata-rata lama sekolah terendah kedua setelah Kabupaten Kepulauan Mentawai. Penanganan rendahnya rata-rata lama sekolah membutuhkan tersedianya data rata-rata lama sekolah yang up to date dan menjangkau level wilayah yang kecil seperti kecamatan dan desa/nagari, agar kebijakan yang diambil pemerintah bisa tepat sasaran. Ketersediaan data tersebut belum mampu diakomodir oleh Badan Pusat Statistik (BPS), karena survei yang dilakukan oleh BPS dirancang untuk pendugaan data area besar, yaitu provinsi dan kabupaten. Salah satu solusi untuk masalah tersebut adalah dengan menggunakan metode estimasi tidak langsung, yaitu Small Area Estimation (SAE). Salah satu estimasi parameter secara tidak langsung berbasiskan model SAE adalah Empirical Best Linear Unbiased Predictor (EBLUP). Tujuan penelitian ini adalah melakukan estimasi rata-rata lama sekolah tingkat kecamatan di Kabupaten Padang Pariaman menggunakan metode EBLUP dengan prosedur maximum likelihood (ML) dan prosedur restricted maximum likelihood (REML). Variabel penyerta yang digunakan dalam penelitian ini yang diduga berpengaruh terhadap variabel respon adalah rasio jumlah SLTA/sederajat per 10.000 penduduk, ratarata jarak terhadap SLTA/sederajat dan persentase keluarga pertanian. Hasil penelitian menunjukkan SAE metode EBLUP dengan prosedur REML menghasilkan nilai estimasi rata-rata lama sekolah tingkat kecamatan di kabupaten Padang Pariaman memiliki akurasi yang lebih baik dibandingkan dengan hasil estimasi langsung (direct) dan prosedur ML.
\end{abstract}

Kata kunci: EBLUP, rata-rata lama sekolah, SAE

\section{ABSTRACT}

The mean years of schooling of the population aged 25 years and over is one indicator that illustrates the overall level of education of the population. Of the 19 districts/cities in West Sumatra, Padang Pariaman District has the second lowest mean years of schooling after the Mentawai Islands District. Handling the low mean years of schooling requires the availability of up to date mean years of schooling data and reaching small regional levels such as sub-districts and villages/nagari, so that the policies taken by the government can be right on target. The availability of this data has not been able to be accommodated by the Central Statistics Agency (BPS), because the survey conducted by BPS is designed to estimate large area data, namely provinces and districts. One solution to this problem is to use the indirect estimation method, namely Small Area Estimation (SAE). One parameter estimation based indirectly on the SAE model is Empirical Best Linear Unbiased Predictor (EBLUP). The purpose of this study is to estimate the mean years of schooling at the subdistrict level in Padang Pariaman using the EBLUP method with the maximum likelihood (ML) procedure and the restricted maximum likelihood (REML) procedure. Accompanying variables used in this study that are thought to influence the response variable are the ratio of the number of senior high school/equivalent per 10,000 population, average distance to high school/equivalent and the percentage of agricultural families. The results showed the SAE of the EBLUP method with the REML procedure produced an estimated value of the 
mean years of schooling in the subdistrict level in Padang Pariaman district having better accuracy than the direct estimation results and the ML procedure.

Keywords: EBLUP, mean years of schooling, SAE

\section{PENDAHULUAN}

Rata-rata lama sekolah penduduk umur 25 tahun ke atas merupakan salah satu indikator yang menggambarkan tingkat pendidikan penduduk secara keseluruhan. Rata-rata lama sekolah merupakan indikator pendidikan yang diformulasikan oleh United Nations Development Programs (UNDP) pada tahun 1990 untuk penyusunan Indeks Pembangunan Manusia (IPM). Dari 19 kabupaten/kota di Sumatera Barat, Kabupaten Padang Pariaman memiliki rata-rata lama sekolah terendah kedua setelah Kabupaten Kepulauan Mentawai. Rata-rata lama sekolah Kabupaten Padang Pariaman tahun 2018 hanya mencapai 7,50 tahun. Angka ini menunjukkan bahwa secara rata-rata pendidikan penduduk umur 25 tahun ke atas baru mencapai jenjang pendidikan kelas 1 SMP (kelas VII) atau putus sekolah di kelas 2 SMP (Kelas VIII). Hal ini masih jauh dari target capaian pendidikan Provinsi Sumatera Barat yang tercantum dalam RPJMD tahun 2016-2021, yaitu rata-rata lama sekolah sekurang-kurangnya 8,72 tahun dapat dicapai pada tahun 2018.

Penanganan rendahnya rata-rata lama sekolah membutuhkan tersedianya data rata-rata lama sekolah yang up to date dan menjangkau level wilayah yang kecil seperti kecamatan dan desa/nagari, agar kebijakan yang diambil pemerintah bisa tepat sasaran. Ketersediaan data tersebut belum mampu diakomodir oleh Badan Pusat Statistik (BPS), karena survei yang dilakukan oleh BPS dirancang untuk pendugaan data area besar, yaitu provinsi dan kabupaten. Salah satu solusi untuk masalah tersebut adalah dengan menggunakan metode estimasi tidak langsung, yaitu Small Area Estimation (SAE). SAE dipilih karena selain bisa digunakan untuk estimasi tingkat wilayah yang kecil, juga mampu mengurangi standard erroryang biasanya dialami jika menggunakan estimasi langsung (direct estimation) dengan jumlah sampel yang kecil (Hidiroglou, 2007). SAE merupakan suatu teknik estimasi parameter area kecil yang memanfaatkan informasi dari dalam area itu sendiri, luar area, dan dari hasil survei atau sensus lain (Longford, 2005). Teknik estimasi seperti ini disebut juga sebagai estimasi tidak langsung (indirect estimation), karena dalam proses estimasi tersebut mencakup data tambahan dari area lain yang digunakan sebagai variabel penyerta. Salah satu estimasi parameter secara tidak langsung berbasiskan model SAE adalah Empirical Best Linear Unbiased Predictor (EBLUP). Metode EBLUP melakukan pendugaan parameter model yang meminimumkan Mean Square Error (MSE) dengan mensubsitusi komponen varians yang tidak diketahui dengan penduga varians dari data sampel (Gosh dan Rao, 1994).

Estimasi wilayah kecil menggunakan SAE dengan metode EBLUP telah dilakukan oleh Srivastava, Sud dan Chandra (2007) yang memperlihatkan bahwa estimasi jumlah pinjaman rumah tangga yang belum lunas dengan metode EBLUP lebih stabil dan lebih efektif daripada direct estimation. Omrani, Gerber dan Bousch (2009) menujukkan bahwa estimasi pengangguran dengan metode EBLUP lebih efisien dibandingkan dengan GREG. Bellow dan Lahiri (2011) juga menunjukkan bahwa estimasi produksi jagung dan kedelai dengan metode EBLUP lebih unggul dibandingkan estimator sintetik. Pendekatan EBLUP dapat diaplikasikan pada linear mixed models (atau dikenal model model FayHerriot) yang biasanya didesain untuk variabel yang memiliki tipe data kontinu, sedangkan EB (Empirical Bayes) dan HB (Hierarchical Bayes) lebih umum diaplikasikan untuk menangani data biner dan cacahan (Rao, 2003). Oleh karena itu metode EBLUP dianggap tepat digunakan pada data kontinu dan bayes dianggap tepat digunakan pada data diskret dan cacahan (Bukhari, 2015). Ratarata lama sekolah merupakan data yang bertipe kontinu. Oleh karena itu, untuk melakukan estimasi rata-rata lama sekolah menggunakan SAE akan lebih tepat jika menggunakan metode EBLUP.

Tujuan penelitian ini adalah melakukan estimasi rata-rata lama sekolah tingkat kecamatan di Kabupaten Padang Pariaman menggunakan metode EBLUP dengan prosedur maximum likelihood (ML) dan prosedur restricted maximum likelihood (REML).

\section{METODE}


Data yang akan digunakan adalah data sekunder yang bersumber dari BPS. Untuk variabel respon yaitu rata-rata lama sekolah, berasal dari data mikro Survei Sosial Ekonomi Nasional (Susenas) di Kabupaten Padang Pariaman tahun 2018, sedangkan variabel penyerta diperoleh dari data mikro pendataan Potensi Desa (Podes) di Kabupaten Padang Pariaman tahun 2018. Unit observasi dalam penelitian ini adalah seluruh kecamatan di Kabupaten Padang Pariaman. Variabel respon diperoleh dengan cara estimasi langsung rata-rata lama sekolah untuk tingkat kecamatan. Variabel penyerta yang digunakan dalam penelitian ini, yang diduga berpengaruh terhadap variabel respon adalah rasio jumlah SLTA/sederajat per 10.000 penduduk $\left(X_{1}\right)$, rata-rata jarak terhadap $\mathrm{SLTA} /$ sederajat $\left(\mathrm{X}_{2}\right)$ dan persentase keluarga pertanian $\left(\mathrm{X}_{3}\right)$.

Metode analisis yang digunakan dalam penelitian ini yaitu analisis pendugaan rata-rata lama sekolah pada level kecamatan menggunakan model Small Area Estimation (SAE) dengan metode Empirical Best Linear Unbiased Predictor (EBLUP), dengan prosedur maximum likelihood (ML) dan prosedur restricted maximum likelihood (REML). Hasil estimasi dari ketiga metode dibandingkan melalui Mean Square Error(MSE).

\section{Model SAE}

Model SAE memperkenalkan model campuran yang menyertakan pengaruh area spesifik yang memperhitungkan variasi antar area diluar yang dijelaskan oleh variabel penyerta yang ada di dalam model. Ketersediaan data dari variabel penyerta akan sangat menentukan kesuksesan dalam pembuatan model SAE. Berdasarkan ketersediaan variabel penyerta ini maka model SAE dapat dikelompokkan menjadi dua jenis yaitu model berbasis area (area level model) dan model berbasis unit (unit level model).

Model level area digunakan jika data penyerta yang bersesuaian dengan data yang diamati tidak tersedia hingga level unit contoh, sedangkan model level unit digunakan jika data penyerta yang bersesuaian dengan data yang diamati tersedia hingga level unit contoh.

Dalam model berbasis area, diasumsikan parameter yang menjadi perhatian di small area ke-i, misalkan $\theta_{i}$ dapat dinyatakan sebagai fungsi yang menghubungkan parameter tersebut dengan variabel bebas yang diukur dari small area adalah (Rao, 2003):

$$
\theta_{i}=\mathbf{x}_{i}^{T} \boldsymbol{\beta}+z_{i} V_{i}, \quad i=1, \ldots, n
$$

dimana

$\beta=\left(\beta_{1}, \beta_{2}, \ldots, \beta_{p}\right)^{T}$ adalah vektor koefisien regresi berukuran $p \times 1$

$\mathbf{x}_{i}=\left(x_{1 i}, x_{2 i}, \ldots, x_{p i}\right)^{T}$ adalah variabel bebas yang diukur dari small area

$n=$ banyaknya smallarea

$z_{i}=$ konstanta positif yang diketahui pada area ke- $i$

$v_{i}=$ pengaruh acak pada area ke- $i$ yang diasumsikan memiliki distribusi $V_{i} \sim N\left(0, \sigma_{v}^{2}\right)$.

Jika $\hat{\theta}_{i}$ adalah penduga langsung yang ada dalam model $\hat{\theta}_{i}=\theta_{i}+e_{i}$ maka model (1) dapat ditulis menjadi:

$$
\hat{\theta}_{i}=\mathbf{x}_{i}^{T} \boldsymbol{\beta}+Z_{i} V_{i}+e_{i}
$$

dengan $e_{i}$ adalah sampling error yang diasumsikan memiliki distribusi $e_{i} \sim N\left(0, \sigma_{e_{i}}^{2}\right)$ dan $\mathrm{V}$ dan $\mathrm{e}$ saling bebas. Model (2) biasa disebut sebagai model Fay-Herriot dengan $z_{i}=1$ (Rao dan Molina, 2015).

\section{Emperical Best Linear Unbiased Prediction Estimator}

Untuk memperoleh penduga BLUP bagi $\theta_{i}$, Rao (2003) mengembangkan teknik penyelesaian generalized linear mixed model. Jika matriks varians kovarians $\mathrm{V}$ dan $\mathrm{e}$ yang tergantung pada vektor parameter dari ragam pengaruh acak $\delta$ diasumsikan diketahui maka penduga BLUP bagi $\theta_{i}$ berdasarkan persamaan (2) adalah 


$$
\tilde{\theta}_{i}^{B L U P}=\gamma_{i} \boldsymbol{\theta}_{i}+\left(1-\gamma_{i}\right) \mathbf{x}_{i}^{T} \boldsymbol{\beta},
$$

dengan

$$
\gamma_{i}=\frac{\sigma_{V}^{2} z_{i}^{2}}{\sigma_{V}^{2} z_{i}^{2}+\sigma_{e}^{2}} \text { dan } \tilde{\boldsymbol{\beta}}=\left(\frac{\sum_{i=1}^{m} x_{i} x_{i}^{T}}{\sigma_{V}^{2} z_{i}^{2}+\sigma_{e}^{2}}\right)^{-1}\left(\frac{\sum_{i=1}^{m} x_{i} \hat{\theta}_{i}}{\sigma_{V}^{2} z_{i}^{2}+\sigma_{e}^{2}}\right)
$$

dan Mean Square Error (MSE)-nya adalah

$$
M S E=g_{1 i}\left(\sigma_{V}^{2}\right)+g_{2 i}\left(\sigma_{v}^{2}\right)
$$

dengan

$$
g_{1 i}\left(\sigma_{V}^{2}\right)=\gamma_{i} \sigma_{e}^{2} \text { dan } g_{2 i}\left(\sigma_{V}^{2}\right)=\left(1-\gamma_{i}\right)^{2} \mathbf{x}_{i}^{T}\left(\frac{\sum_{i=1}^{m} x_{i} x_{i}^{T}}{\sigma_{V}^{2} z_{i}^{2}+\sigma_{e}^{2}}\right) \mathbf{x}_{i}
$$

Metode BLUP yang dikembangkan Henderson di atas mengasumsikan diketahuinya komponen ragam pengaruh acak dalam model linier campuran, padahal dalam kenyataannya komponen ragam ini tidak diketahui. Oleh karena itu perlu dilakukan pendugaan komponen ragam $\delta$ agar penduga BLUP dapat diketahui nilainya. Harville (1977) mengenalkan metode pendugaan komponen ragam yaitu metode Maximum Likelihood (ML) dan metode Restricted Maximum Likelihood (REML). Dalam mengestimasi komponen ragam $\delta$, Rao (2003) memperkenalkan metode Newton-Rapson atau scoring alghorithm. Scoring alghorithm untuk ML adalah

$$
\hat{\boldsymbol{\delta}}^{(a+1)}=\hat{\boldsymbol{\delta}}^{(a)}+\left[I\left(\hat{\boldsymbol{\delta}}^{(a)}\right)\right]^{-1} S\left(\hat{\boldsymbol{\delta}}^{(a)}\right)
$$

dengan

$$
I(\hat{\boldsymbol{\delta}})=\frac{1}{2} \sum_{i=1}^{m} \frac{z_{i}^{4}}{\left(\sigma_{V}^{2} z_{i}^{2}+\sigma_{e}^{2}\right)^{2}} \operatorname{dan} S(\hat{\boldsymbol{\delta}})=-\frac{1}{2} \sum_{i=1}^{m} \frac{z_{i}^{2}}{\left(\sigma_{V}^{2} z_{i}^{2}+\sigma_{e}^{2}\right)^{2}}+\frac{1}{2} \sum_{i=1}^{m} \frac{z_{i}^{2}\left(\hat{\theta}_{i}-\mathbf{x}_{i}^{T} \boldsymbol{\beta}\right)}{\left(\sigma_{V}^{2} z_{i}^{2}+\sigma_{e}^{2}\right)^{2}}
$$

sedangkan scoring alghorithm REML adalah

$$
\hat{\boldsymbol{\delta}}^{(a+1)}=\hat{\boldsymbol{\delta}}^{(a)}+\left[I_{R}\left(\hat{\boldsymbol{\delta}}^{(a)}\right)\right]^{-1} S_{R}\left(\hat{\boldsymbol{\delta}}^{(a)}\right)
$$

dengan

$$
\begin{aligned}
& I(\hat{\boldsymbol{\delta}})=\frac{1}{2} \operatorname{tr}(\mathrm{PBPB}), \\
& \mathbf{P}=\mathbf{V}^{-1}-\mathbf{V}^{-1} \mathbf{X}\left(\mathbf{X V}^{-1} \mathbf{X}^{T}\right)^{-1} \mathbf{X}^{T} \mathbf{V}^{-1}, \\
& \mathbf{B}=\operatorname{diag}\left(z_{i}^{2}\right) \operatorname{dan} \\
& S(\hat{\boldsymbol{\delta}})=-\frac{1}{2} \operatorname{tr}(\mathrm{PB})+\frac{1}{2} \hat{\boldsymbol{\theta}}^{T} \mathrm{PBP} \hat{\boldsymbol{\theta}} .
\end{aligned}
$$

Penduga EBLUP dapat ditulis

$$
\hat{\theta}_{i}^{E B L U P}=\gamma_{i} \hat{\boldsymbol{\theta}}_{i}+\left(1-\gamma_{i}\right) \mathbf{x}_{i}^{T} \hat{\boldsymbol{\beta}},
$$

dan MSE EBLUP dapat ditulis sebagai berikut:

$$
\operatorname{MSE}\left[\hat{\theta}_{i}^{E B L U P}\right]=g_{1 i}(\hat{\delta})+g_{2 i}(\hat{\delta})+2 g_{3 i}(\hat{\delta})
$$

dengan

$$
g_{3 i}(\delta)=\left(\frac{\left(z_{i}^{2} \sigma_{e}^{2}\right)^{2}}{\left(\sigma_{V}^{2} z_{i}^{2}+\sigma_{e}^{2}\right)^{3}}\right) \operatorname{Var}\left(\hat{\sigma}_{V}^{2}\right)
$$

\section{HASIL DAN PEMBAHASAN}


Estimasi langsung rata-rata lama sekolah dilakukan pada 17 kecamatan yang ada di Kabupaten Padang Pariaman berdasarkan data mikro Susenas tahun 2018. Hasil estimasi langsung dapat dilihat pada Tabel 1. Berdasarkan hasil estimasi langsung, diperoleh kecamatan dengan rata-rata lama sekolah terendah berada di Kecamatan VII Koto Sungai Sariak dengan rata-rata lama sekolah 5,85 tahun (setara kelas 6 SD) dan rata-rata lama sekolah tertinggi berada di Kecamatan Enam Lingkung dengan rata-rata lama sekolah 10,32 tahun (setara kelas 1 SMA). Dapat dilihat juga nilai MSE setiap kecamatan sehingga diperoleh rata-rata MSE kecamatan di Kabupaten Padang Pariaman sebesar 19,36 .

Tabel 1. Estimasi Langsung (Direct) Rata-rata Lama Sekolah, MSE dan Jumlah Rumah Tangga Sampel

\begin{tabular}{lccc}
\hline \multicolumn{1}{c}{ Kecamatan } & $\begin{array}{c}\text { Rata-rata lama } \\
\text { sekolah }\end{array}$ & MSE & $\begin{array}{c}\text { Jumlah Rumah Tangga } \\
\text { Sampel }\end{array}$ \\
\hline Batang Anai & 8,31 & 18,743 & 297 \\
Lubuk Alung & 9,90 & 17,522 & 325 \\
Sintuk Toboh Gadang & 7,88 & 19,444 & 136 \\
Ulakan Tapakis & 6,00 & 18,951 & 91 \\
Nan Sabaris & 7,93 & 22,093 & 192 \\
2X11 Enam Lingkung & 8,07 & 21,012 & 86 \\
Enam Lingkung & 10,32 & 16,466 & 155 \\
2X11 Kayu Tanam & 6,11 & 14,882 & 84 \\
VII Koto Sungai Sariak & 5,85 & 18,228 & 210 \\
Patamuan & 6,70 & 22,293 & 32 \\
Padang Sago & 7,58 & 24,017 & 87 \\
V Koto KP Dalam & 7,32 & 23,027 & 180 \\
V Koto Timur & 8,48 & 20,211 & 134 \\
Sungai Limau & 8,72 & 17,514 & 131 \\
Batang Gasan & 7,24 & 20,818 & 81 \\
Sungai Geringging & 6,74 & 20,175 & 170 \\
IV Koto Aur Malintang & 6,61 & 13,727 & 115 \\
\hline
\end{tabular}

Sebelum melakukan SAE dengan metode EBLUP, terlebih dahulu dilakukan uji normalitas terhadap hasil estimasi langsung rata-rata lama sekolah menggunakan uji kolmogorof-smirnov. Berdasarkan hasil uji kenormalan data rata-rata lama sekolah diperoleh nilai statistik kolmogorofsmirnov adalah 0,110 dan nilai $p$-value adalah $>0,150$. Karena nilai $p$-value lebih dari 0,05 maka dapat disimpulkan bahwa data estimasi langsung rata-rata lama sekolah tingkat kecamatan di Kab. Padang Pariaman berdistribusi normal. Sehingga dalam hal ini SAE dengan metode EBLUP dapat digunakan.

Selanjutnya, pada tahapan estimasi rata-rata lama sekolah tingkat kecamatan dengan EBLUP membutuhkan beberapa variabel penyerta yang diperoleh dari Podes. Pemilihan variabel penyerta dilakukan dengan cara mencari variabel yang berkorelasi signifikan dan variabel yang telah dibangun pada penelitian terdahulu terhadap rata-rata lama sekolah. Variabel yang terpilih adalah rasio jumlah SLTA/sederajat per 10.000 penduduk $\left(X_{1}\right)$, rata-rata jarak terhadap SLTA/sederajat $\left(X_{2}\right)$ dan persentase keluarga pertanian $\left(\mathrm{X}_{3}\right)$.

Hasil penelitian menunjukkan SAE metode EBLUP dengan prosedur REML menghasilkan nilai estimasi rata-rata lama sekolah tingkat kecamatan di kabupaten Padang Pariaman memiliki akurasi yang lebih baik dibandingkan dengan hasil estimasi langsung (direct) dan prosedur ML. Hal ini dilihat boxplot nilai Mean Square Error (MSE) masing-masing prosedur (Gambar 1). Boxplot MSE estimasi dengan prosedur REML mempunyai median yang jauh lebih rendah dibandingkan dengan metode estimasi langsung (direct) dan prosedur ML. 


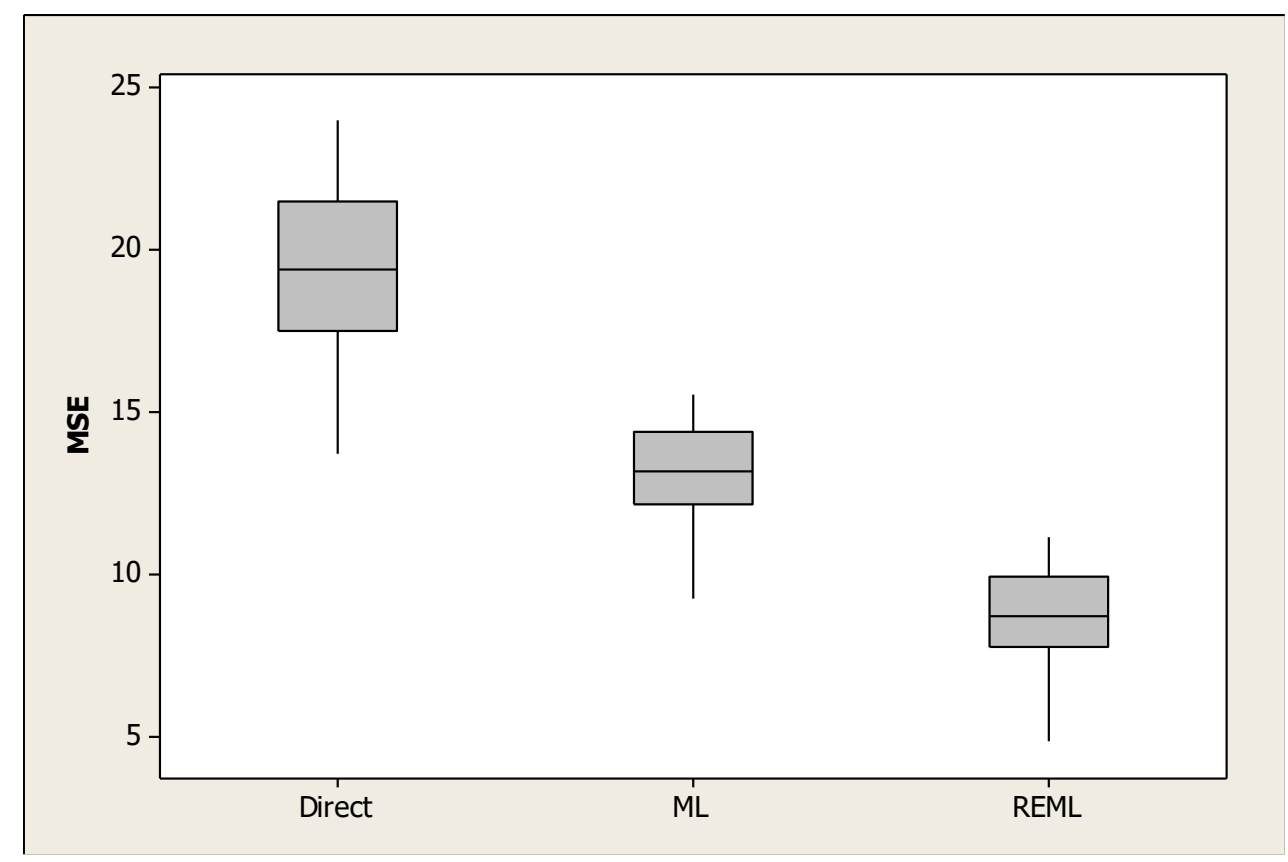

Gambar 1. Boxplot Nilai MSE antara Metode Estimasi Langsung (Direct), ML dan REML

Hasil estimasi rata-rata lama sekolah berdasarkan metode EBLUP dengan prosedur REML dapat dilihat pada Gambar 2. Secara keseluruhan estimasi rata-rata lama sekolah pada tingkat kecamatan di Kabupaten Padang Pariaman tertinggi adalah sebesar 8,78 tahun yang berada di Kecamatan Batang Anai dan terendah sebesar 6,87 di Kecamatan Sungai Geringging.

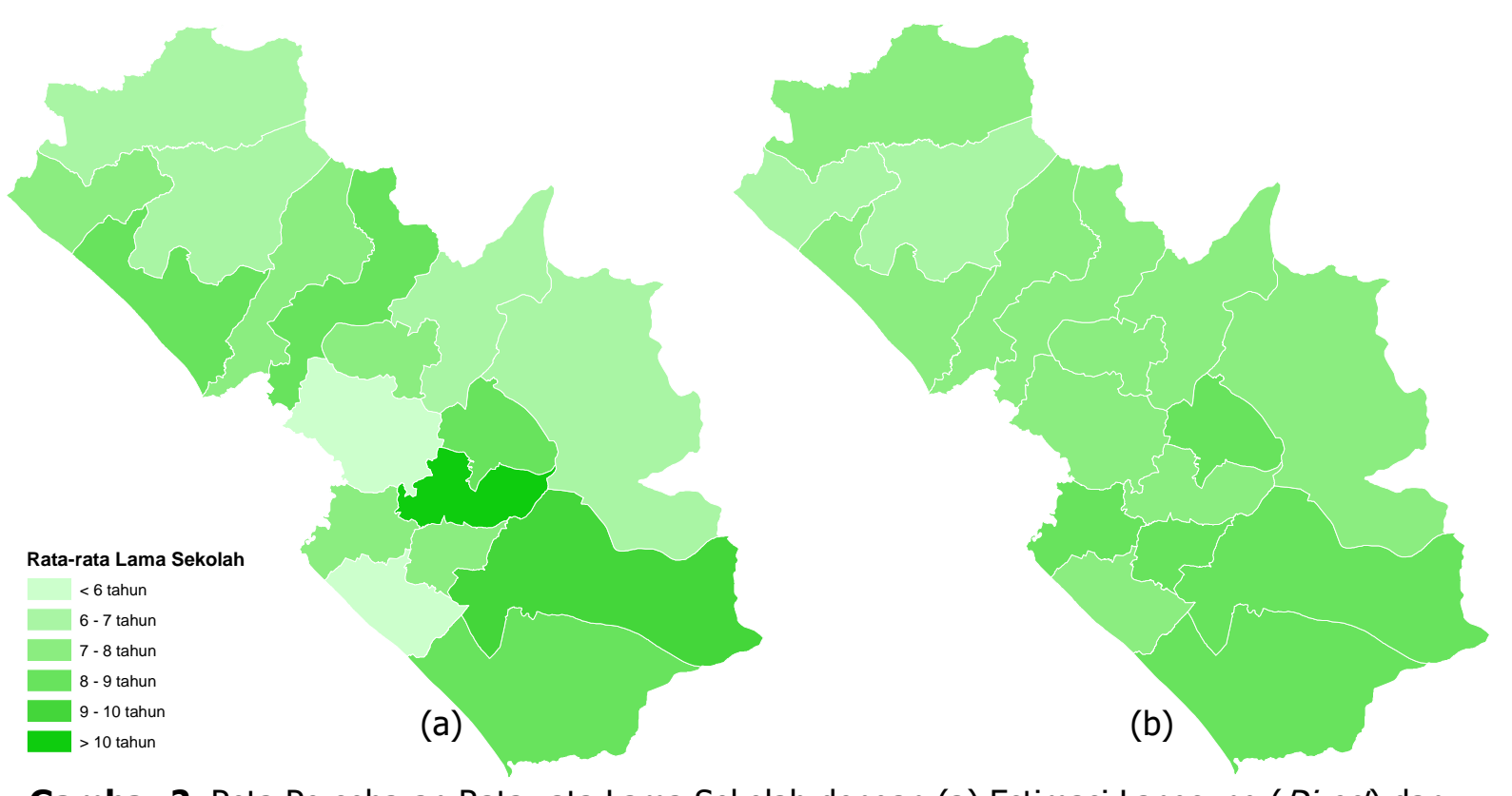

Gambar 2. Peta Persebaran Rata-rata Lama Sekolah dengan (a) Estimasi Langsung (Direct) dan (b) Estimasi Metode EBLUP REML di Kabupaten Padang Pariaman Tahun 2018

\section{KESIMPULAN}

Hasil estimasi rata-rata lama sekolah tingkat kecamatan di Kabupaten Padang Pariaman berdasarkan metode EBLUP dengan prosedur REML lebih baik dibandingkan dengan hasil estimasi langsung (direct) dan hasil EBLUP dengan prosedur ML karena mampu meminimumkan error. Hal ini terlihat dari nilai MSE yang dihasilkan ketiga metode tersebut. Untuk analisis lebih lanjut bisa 
dilakukan estimasi rata-rata lama sekolah tingkat desa/nagari dengan menggunakan variabel bebas yang lain agar dapat menggambarkan rata-rata lama sekolah dengan lebih baik.

\section{DAFTAR PUSTAKA}

Bukhari, A.S. (2015), Pendugaan Area Kecil Komponen Indeks Pendidikan Dalam IPM di Kabupaten Indramayu dengan Metode Hierarchical Bayes Berbasis Spasial, Tesis, Universitas Padjadjaran (UNPAD), Bandung.

Bellow, M. E. Dan Lahiri, P. S. (2011). An Empirical Best Linear Unbiased Prediction Approach to Small-Area Estimation of Crop Parameters. Proceedings of Section on Survey Research Methods, American Statistical Association, 3976-3985.

Ghosh, M. dan Rao, J. N. K. (1994). Small area estimation: an appraisal. Statistical science, 55-76.

Harville, D.A. (1977) Maximum Likelihood Approaches to Variance Components Estimation and to Related Problems. Journal of the American Statistical Association, 72, 320-338. http://dx.doi.org/10.1080/01621459.1977.10480998

Hidiroglou, M. (2007). Small-Area Estimation: Theory and Practice. In Proceedings of the Survey Research Methods Section, 3445-3456.

Longford, N.T. (2005). Missing Data and Small Area Estimation: Modern Analytical Equipment for the Survey Statistician. New York: Springer Science+Business Media, Inc.

Omrani, H., Gerber, P. dan Bousch, P. (2009). Model-Based Small Area Estimation with application to unemployment estimates. World Academy of Science, Engineering and Technology, 49, 793-800.

Rao, J. N. K. (2003). Small area estimation. John Wiley \& Sons, Inc.. New Jersey.

Rao, J. N. K. dan Molina. (2015). Small Area Estimation 2nd Edition. New York: John Wiley and Sons. Inc.

Srivastava, A. K., Sud, U. C. dan Chandra, H. (2007). Small area estimation-An application to national sample survey data. Journal of the Indian Society of Agricultural Statistics, 61(2), 249-254. 